\title{
Application of Rayleigh Wave Inversion for Void Detection Using Multichannel Analysis of Surface Waves (MASW)
}

Lindsey Riikola, Md. Iftekhar Alam

The University of Tennessee, Knoxville 


\section{Objectives}

- To understand the techniques and processes of shallow subsurface investigation for void detection using Multichannel Analysis of Surface Waves (MASW).

- To investigate the nature of the shear wave velocity changes across a void in unconsolidated sediments. 


\section{Presentation Outline}

- Objectives

- Location and Geology

- Survey Methods and Data Acquisition

- Results

- Discussion 


\section{Location and Geology}

- The study site is located at the main campus of Oklahoma State University in Payne County, OK.

- Payne County generally has a flat-lying surface of Quaternary sediments over Pennsylvanian and Permian age rock.

- The surrounding areas have a surface geology of alternating beds of mudstone, sandstone, and carbonates (Shelton et al., 1985).

- The top part of the study site has a lithology that varies from unsaturated to partially saturated sandy clay where the anomalies (pipes) are located.

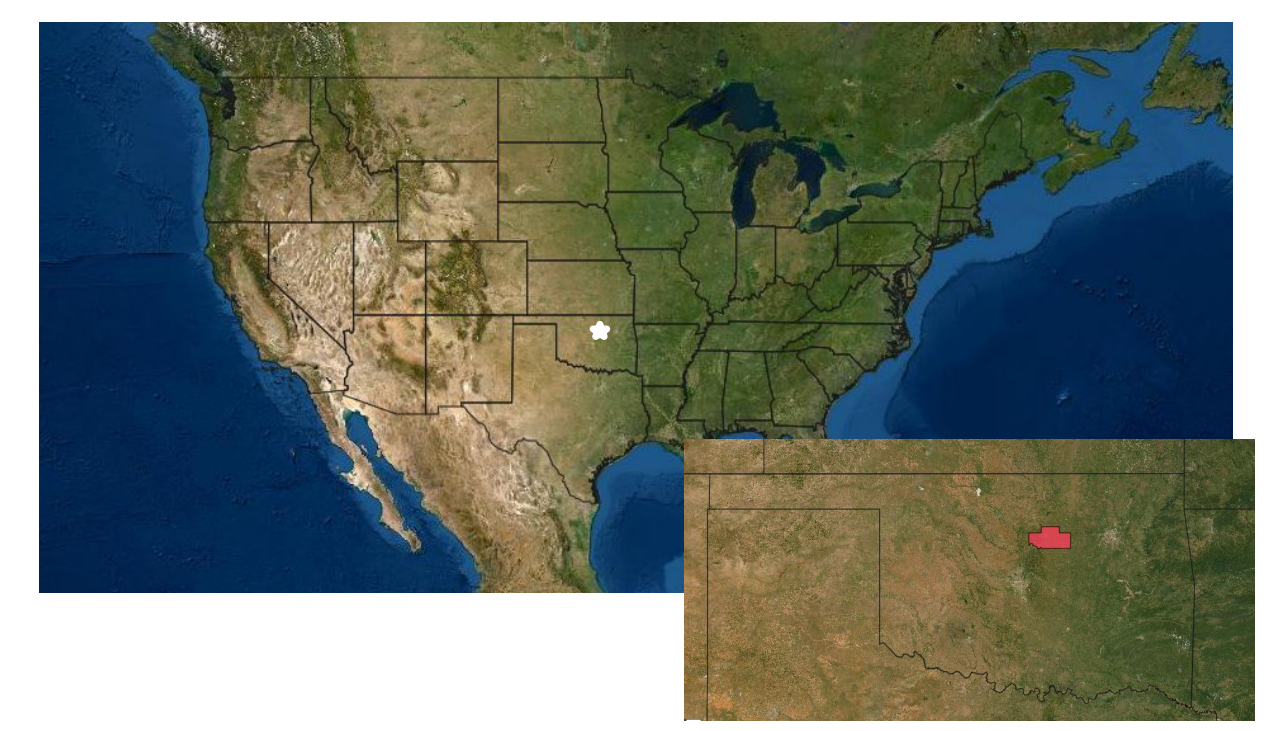




\section{Site History}

- The site had likely experienced backfilling and excavation during construction because of the location being in the center of campus.

- The deeper geology remains unexplored in this project as the depth of investigation extends only a few meters from the ground surface.

- Several pipes were laid below the ground surface at different depths for various purposes, e.g., water lines, sewage lines, storm sewers, etc. 


\section{Data Acquisition}

- The seismic data was acquired along a $57 \mathrm{~m}$ long 2D profile (white line), oriented $\mathrm{N}-\mathrm{S}$ over a storm drainage pipe ( $1 \mathrm{~m}$ in diameter, blue line) and a water pipe ( $0.8 \mathrm{~m}$ in diameter, yellow line), which are orthogonal to the orientation of the
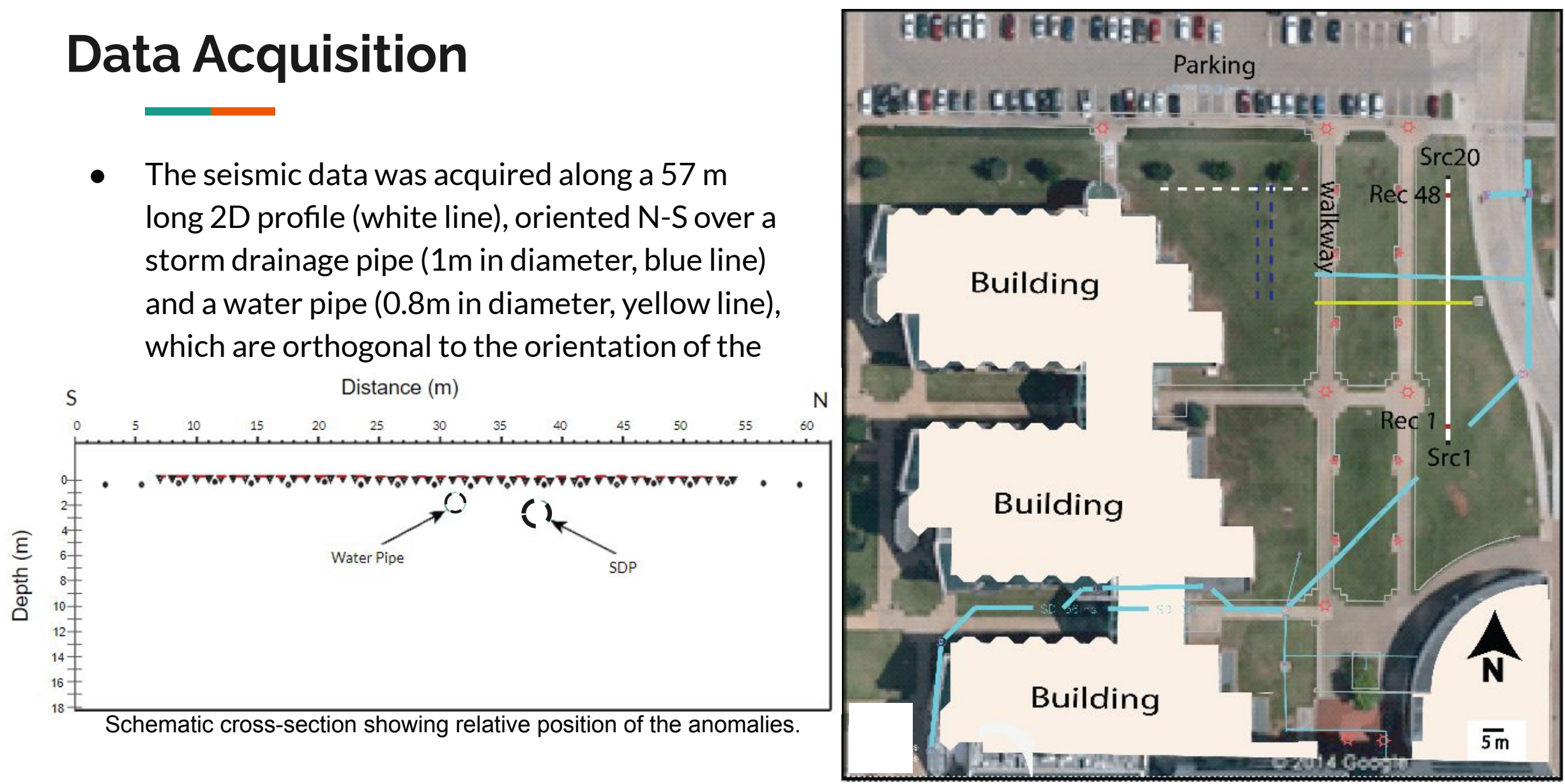


\section{Methods/Data Acquisition}

- The data was obtained in split-spread geometry.

- There were 48 geophones placed at $1 \mathrm{~m}$ interval and the shot intervals are $3 \mathrm{~m}$.

- The source used in this experiment for data acquisition was a Betsy Seisgun with 12-gauge 400-grain shells, which creates vertical and horizontal seismic waves (Fertig, 1984).

- The source was placed between the receivers.

- The receivers were single component $40 \mathrm{~Hz}$ vertical geophones.

- Data was recorded with a sampling interval of $0.25 \mathrm{~ms}$.

\begin{tabular}{|c|c|}
\hline $\begin{array}{l}\text { Acquisition } \\
\text { Parameters }\end{array}$ & Vertical \\
\hline Profile Length & $57 \mathrm{~m}$ \\
\hline No of Channels & 48 \\
\hline Receiver Interval & $1 \mathrm{~m}$ \\
\hline Shot Interval & $3 \mathrm{~m}$ \\
\hline No of Shots & 20 \\
\hline Source & $\begin{array}{l}\text { Betsy Seisgun with } \\
\text { 12-gauge } 200 \text { grain } \\
\text { shells }\end{array}$ \\
\hline Sample Interval & $0.25 \mathrm{~ms}$ \\
\hline Shooting Method & Split spread \\
\hline $\begin{array}{l}\text { Acquisition } \\
\text { Template }\end{array}$ & Dynamic \\
\hline
\end{tabular}




\section{Methods/Data Acquisition}

- In total, 960 traces were recorded using both vertical and horizontal geophones, however we are only presenting the data recorded with vertical component geophones.

- Overall, the unprocessed field data is clean with relatively low, random noise.

- The first arrival times from the vertical components generally increased with source-receiver offsets.

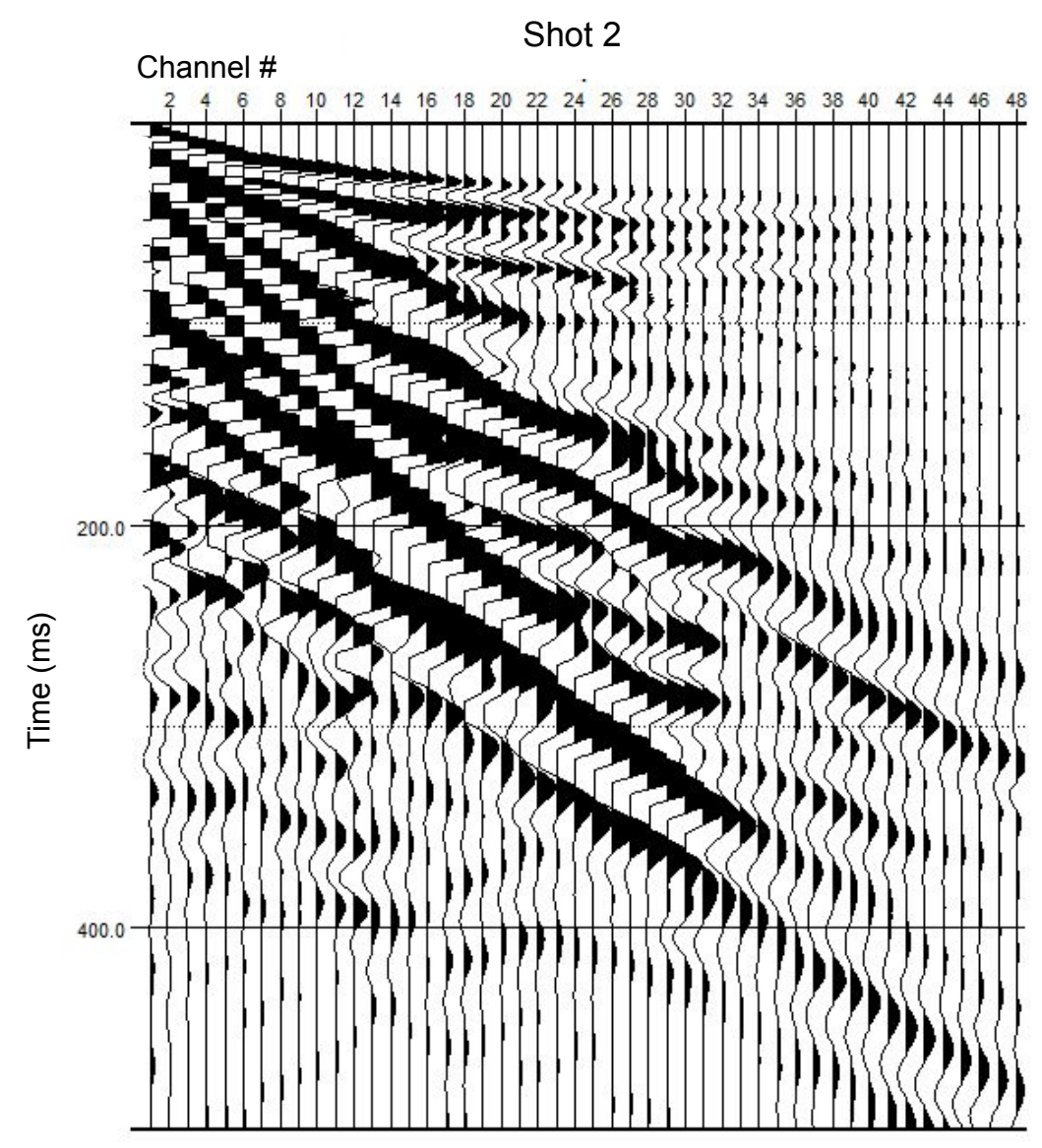




\section{Data Processing}

- Initial processing involved general muting and editing of the data to eliminate the noisy traces along with a faulty geophone, which are not considered for inversion.

- Data processing removes various, unwanted noises and the data which is particularly not useful.

- In this study, the specified region of interest is the ground roll.

- Trace killing, frequency filtering and muting are applied to remove random noise before dispersion curve analysis. 


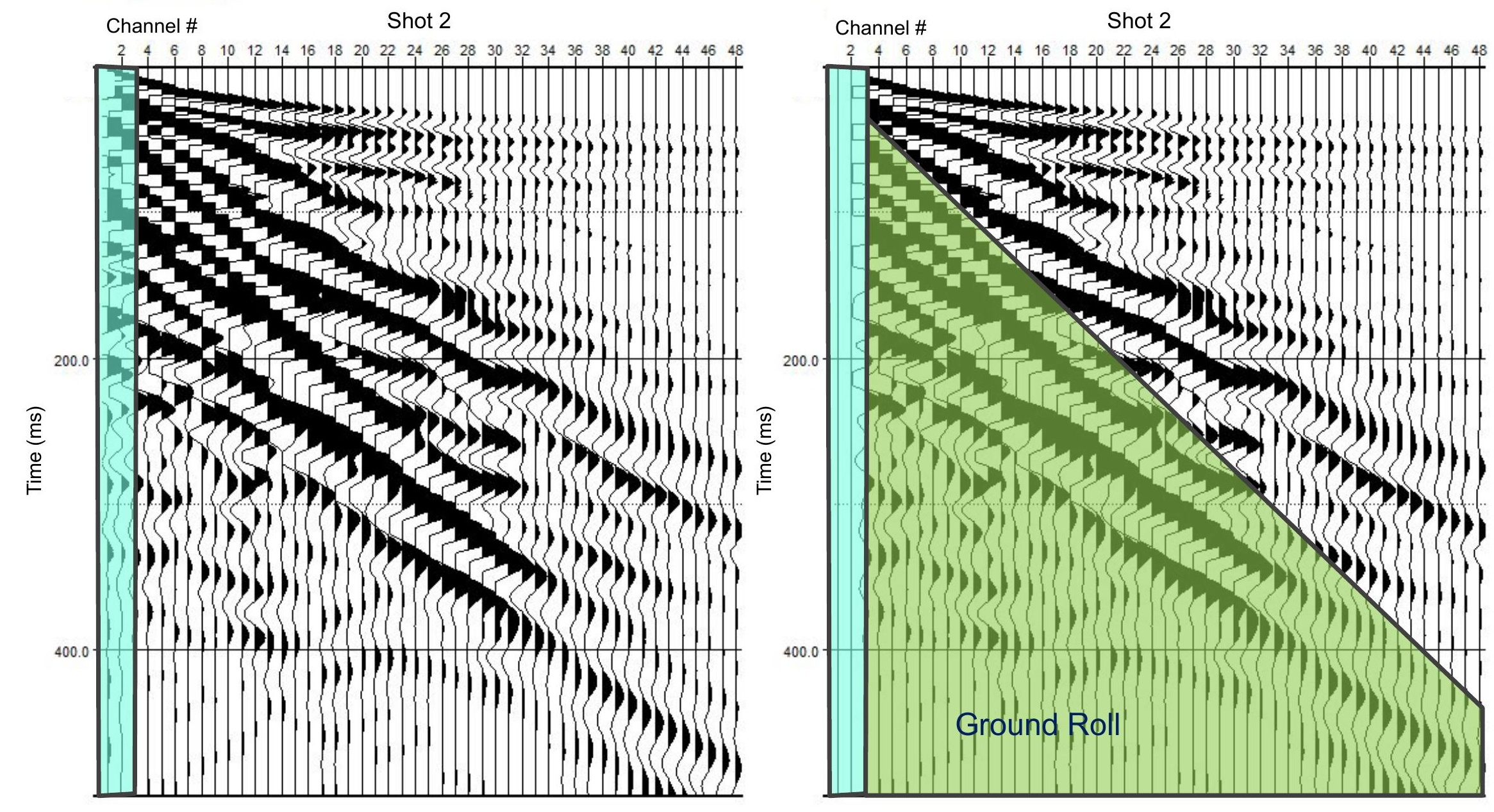




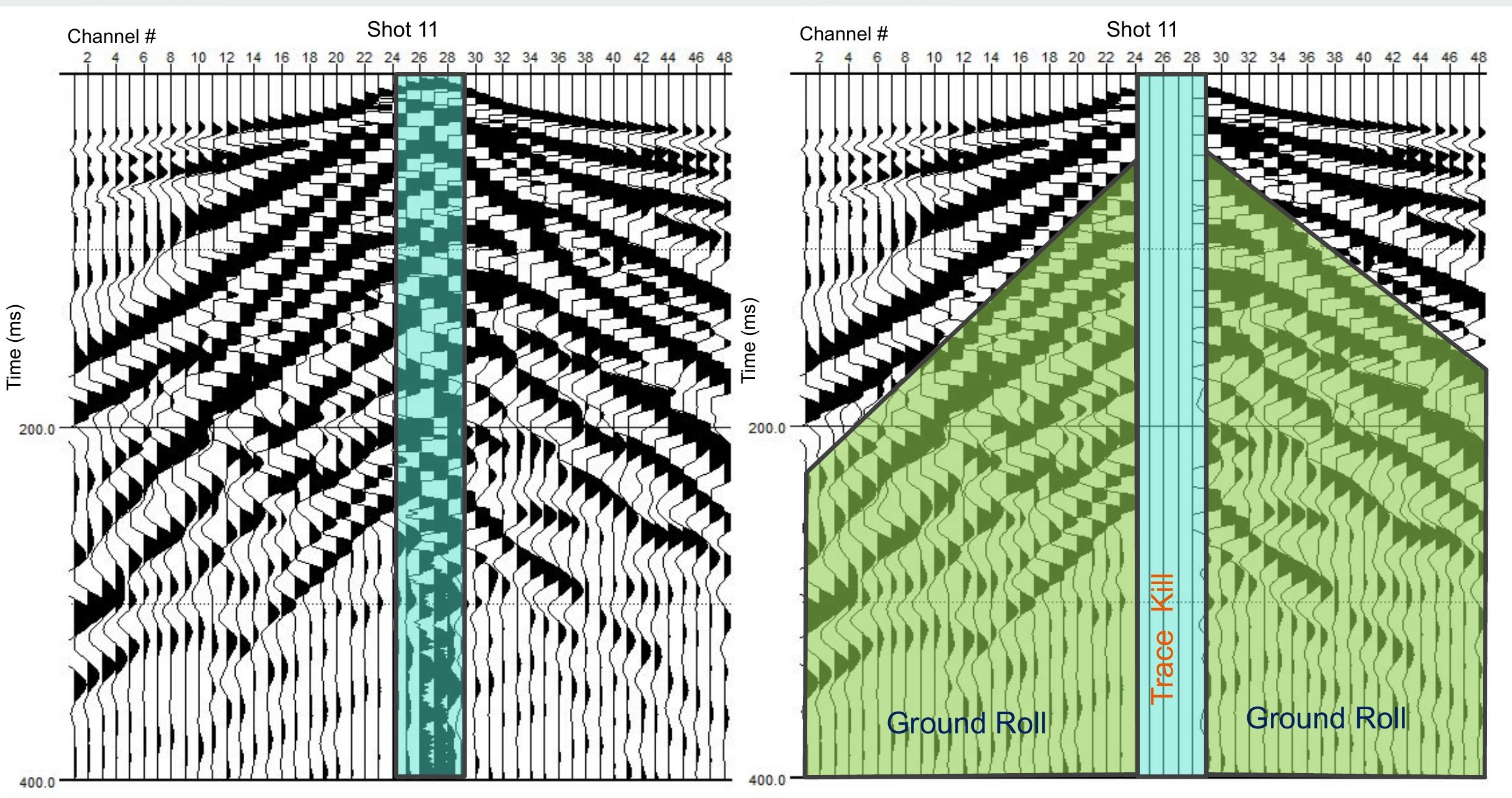



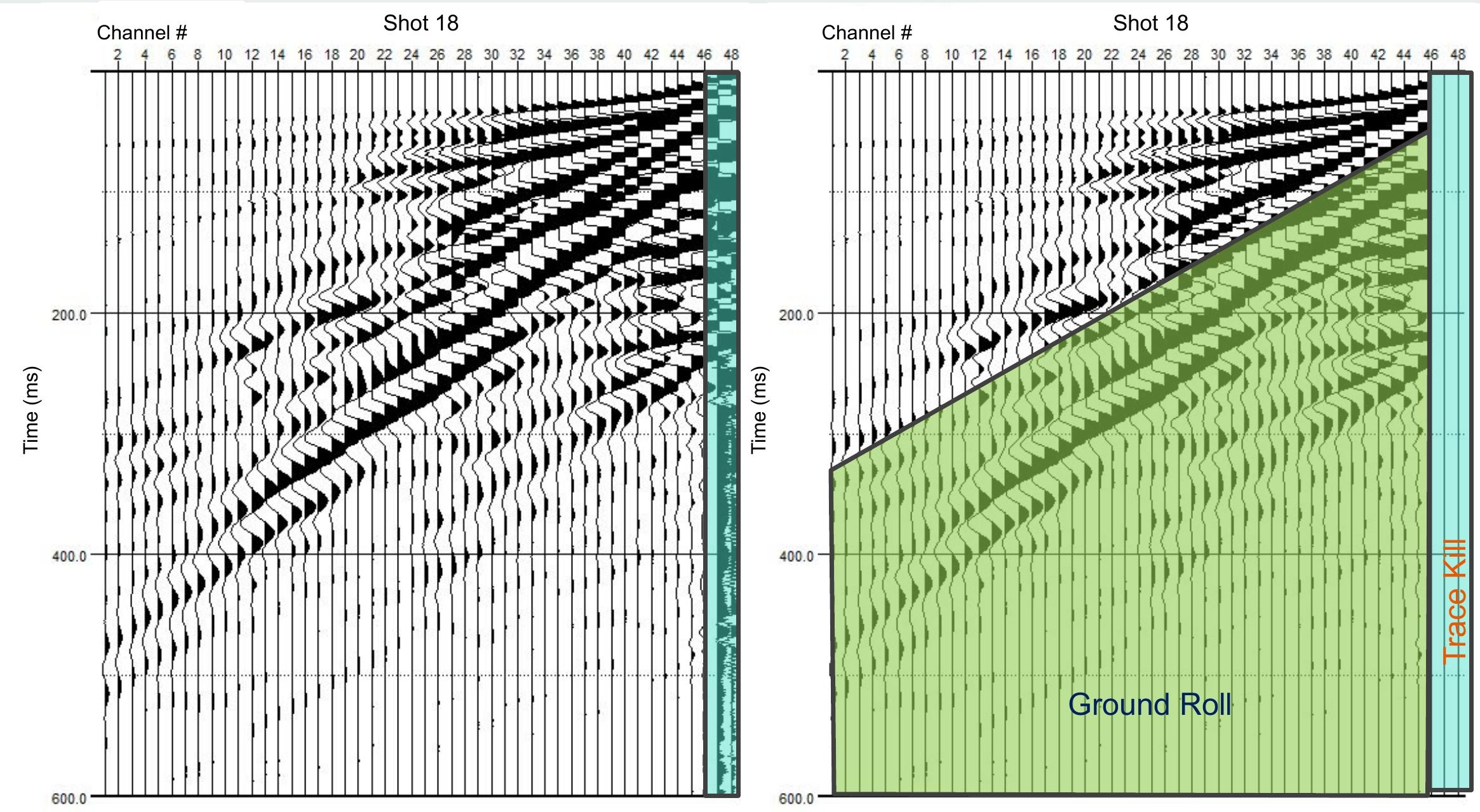


\section{Models}

- Shot 2 raw data

\section{Shot 2}

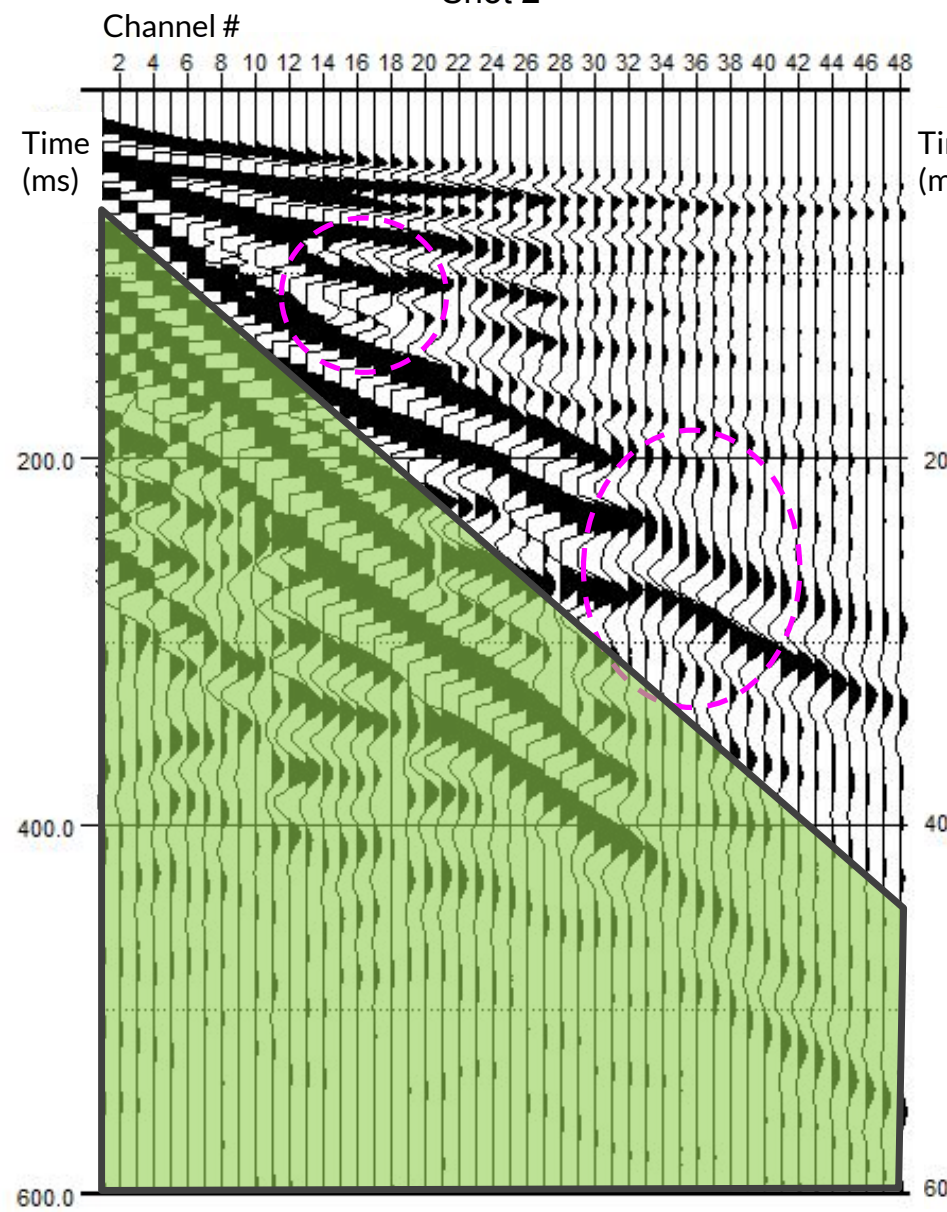

Channel \#

Shot 2 $\stackrel{2}{1}$ e

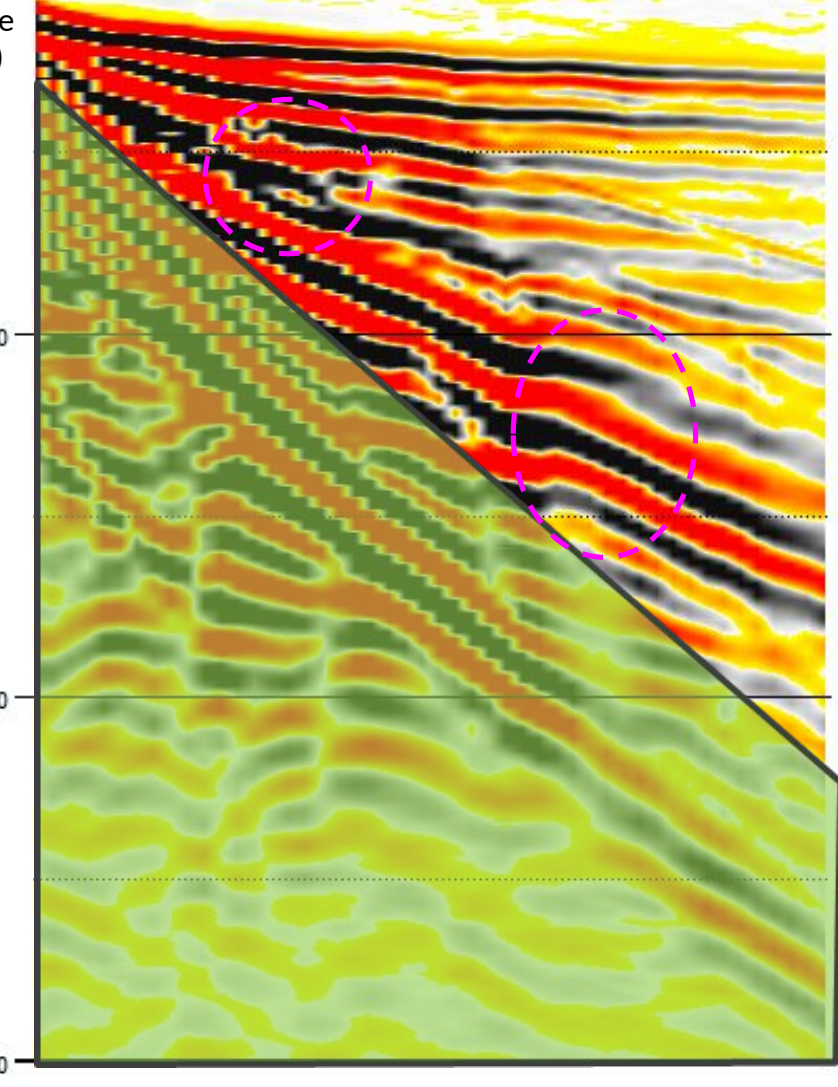




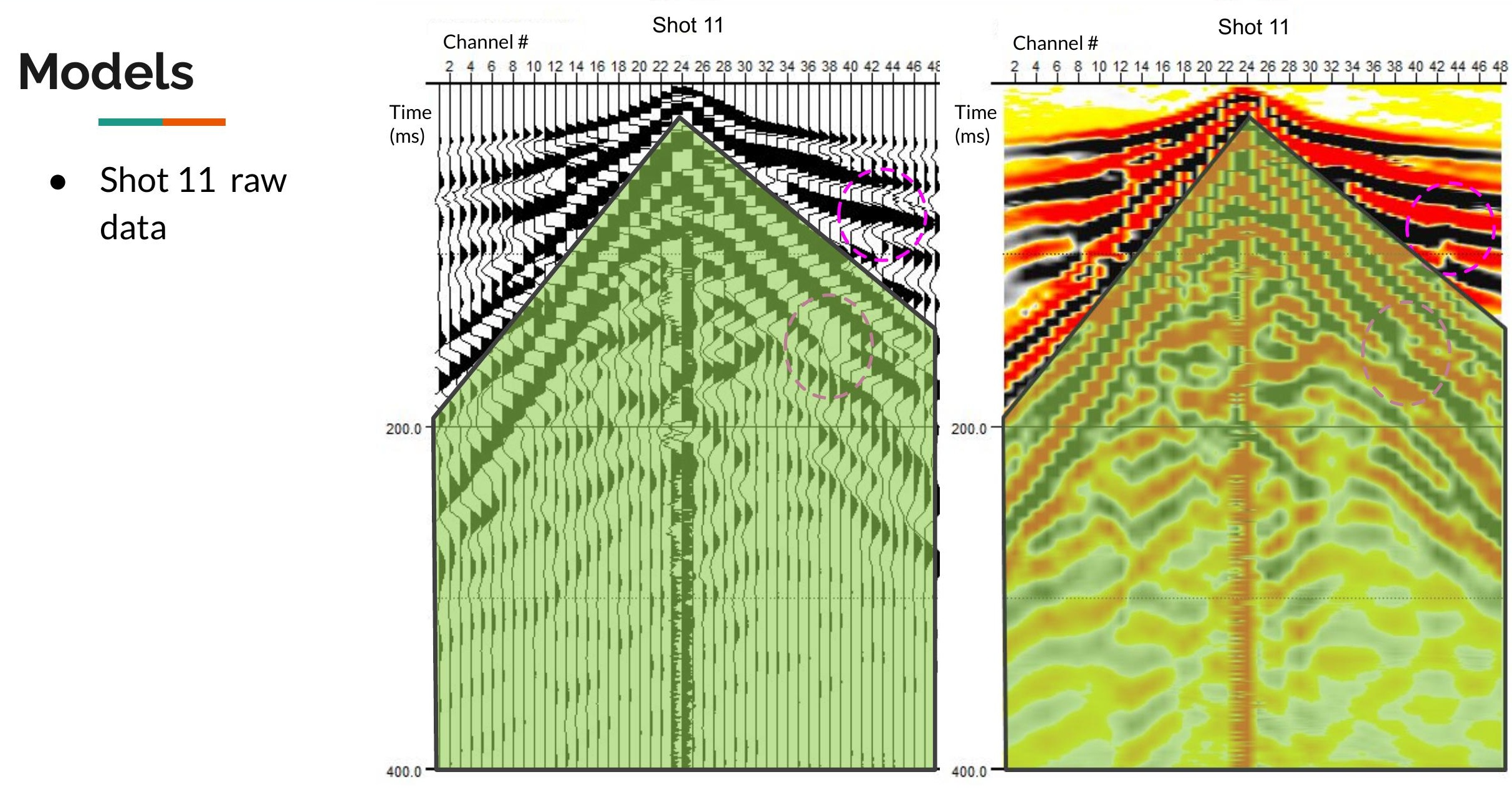




\section{Models}

- Shot 18 raw data

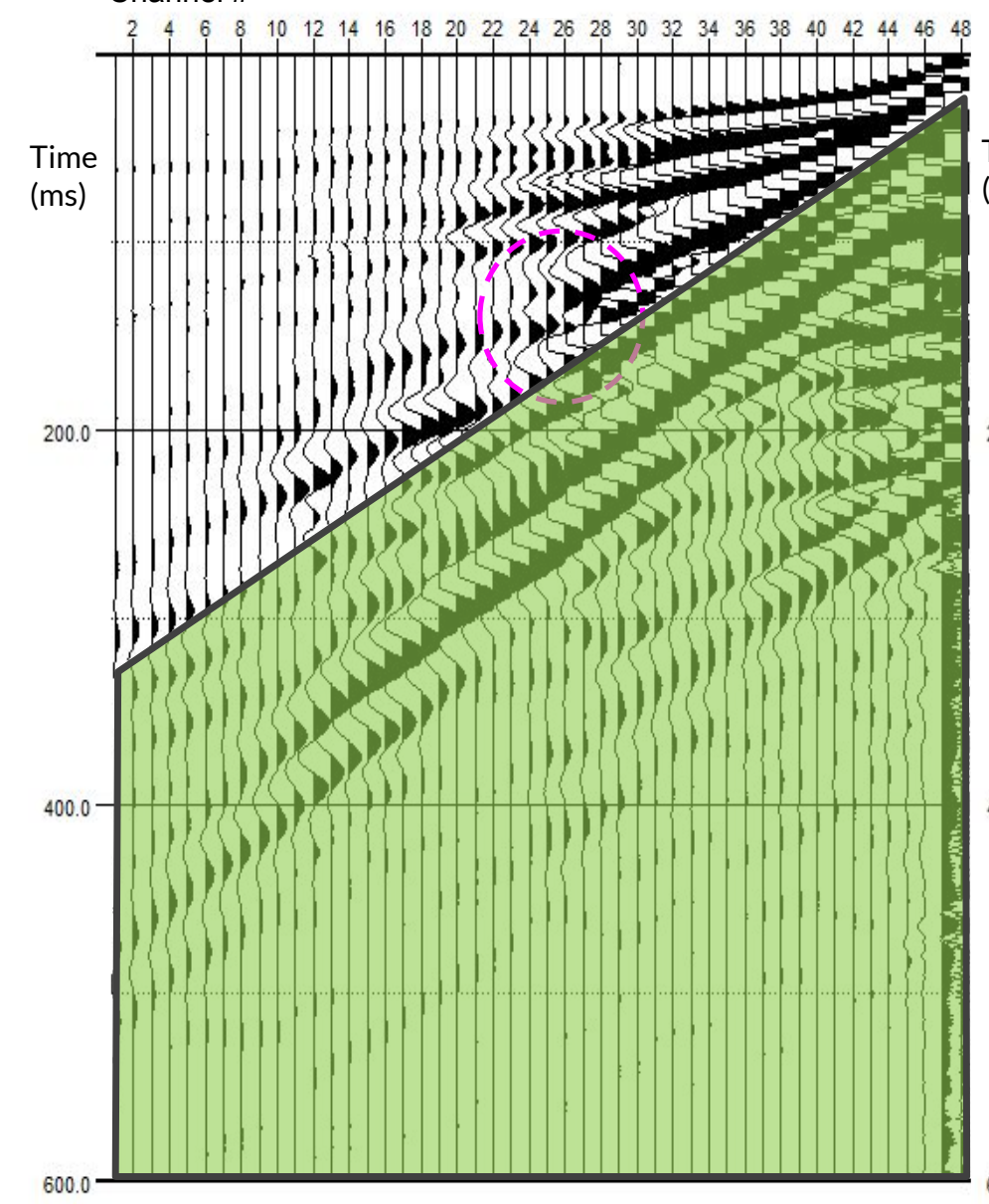

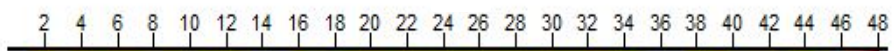

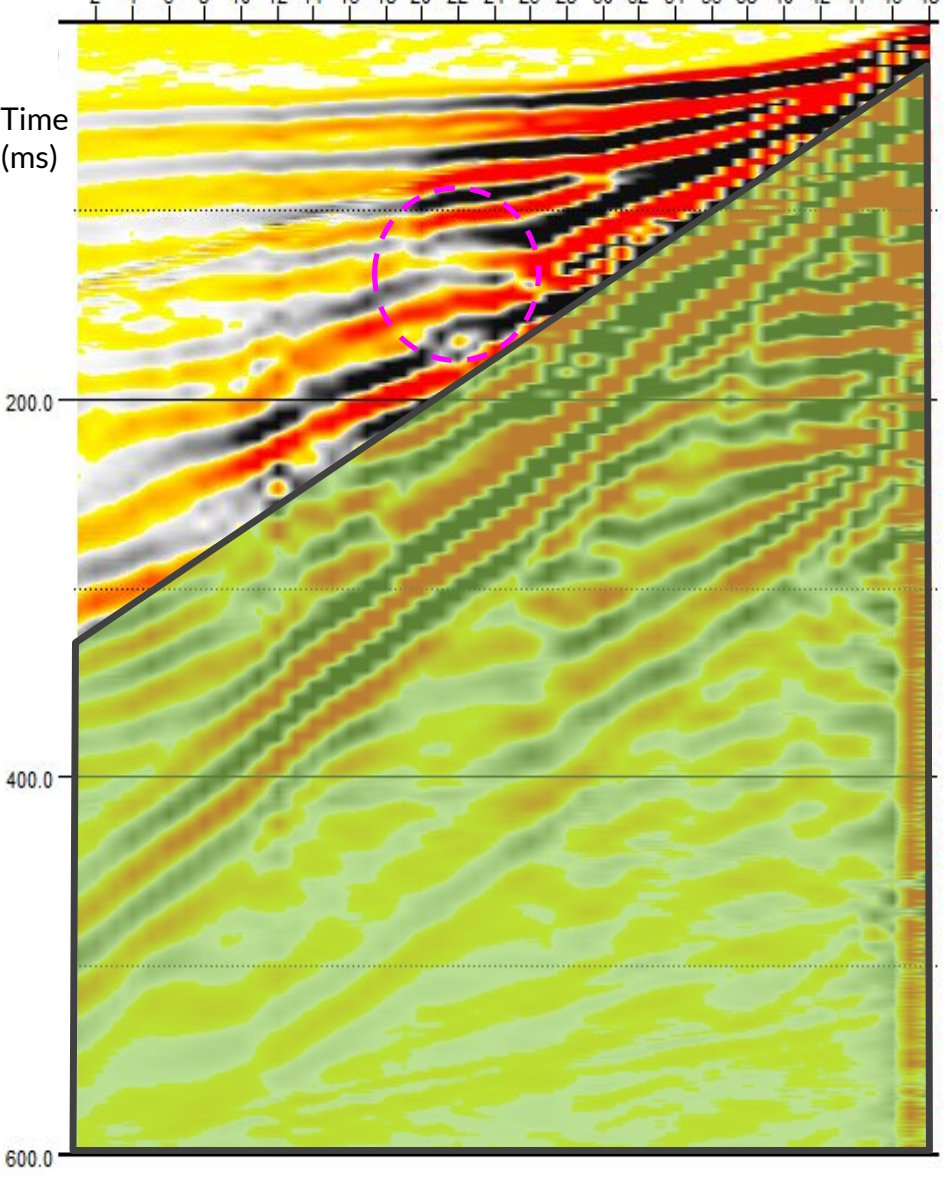




\section{Dispersion}

Curve Analysis

- Shot 2 dispersion curve
Velocity (ms)

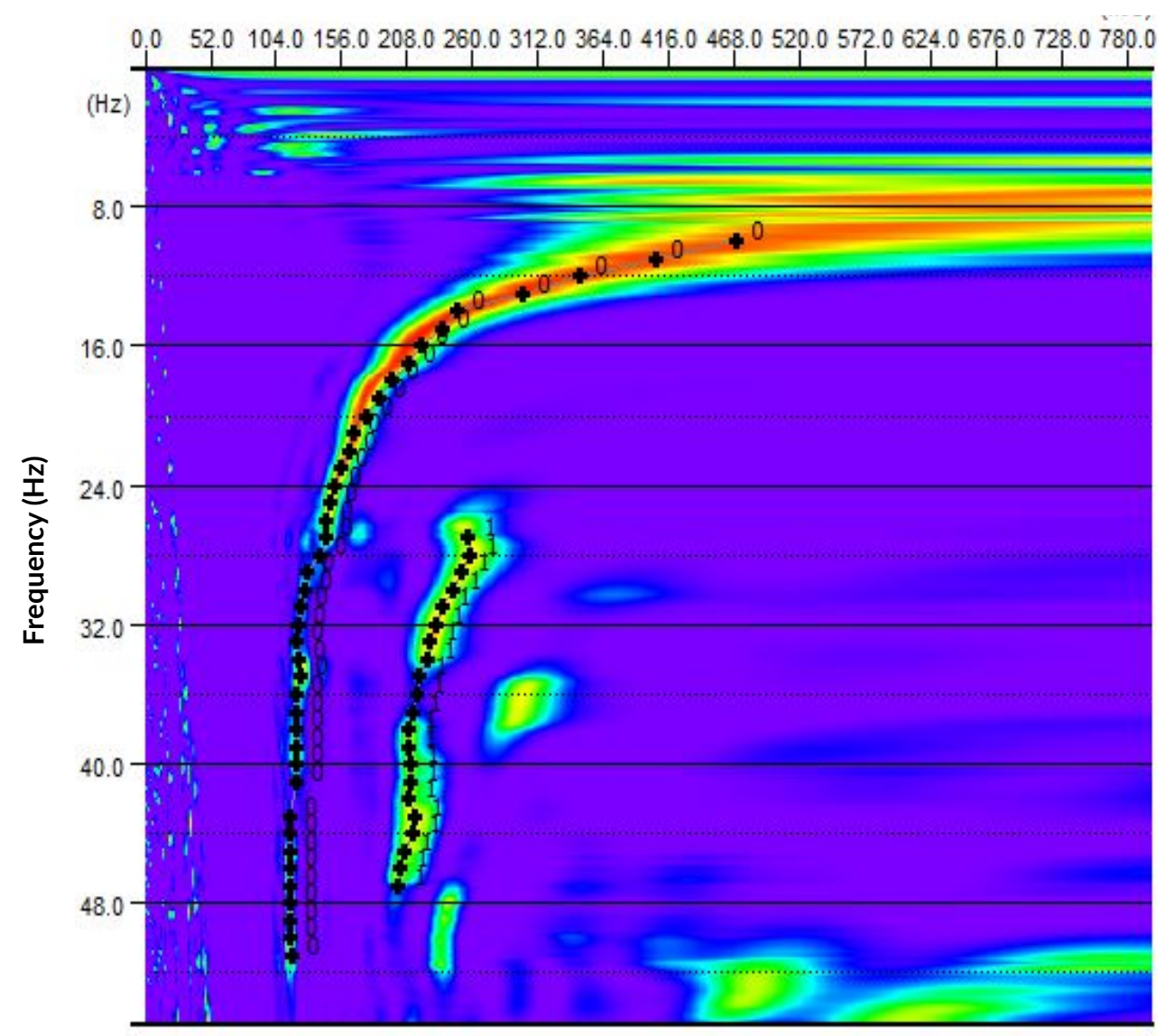




\section{Dispersion}

Curve Analysis

- Shot 11 dispersion curve
Velocity (ms)

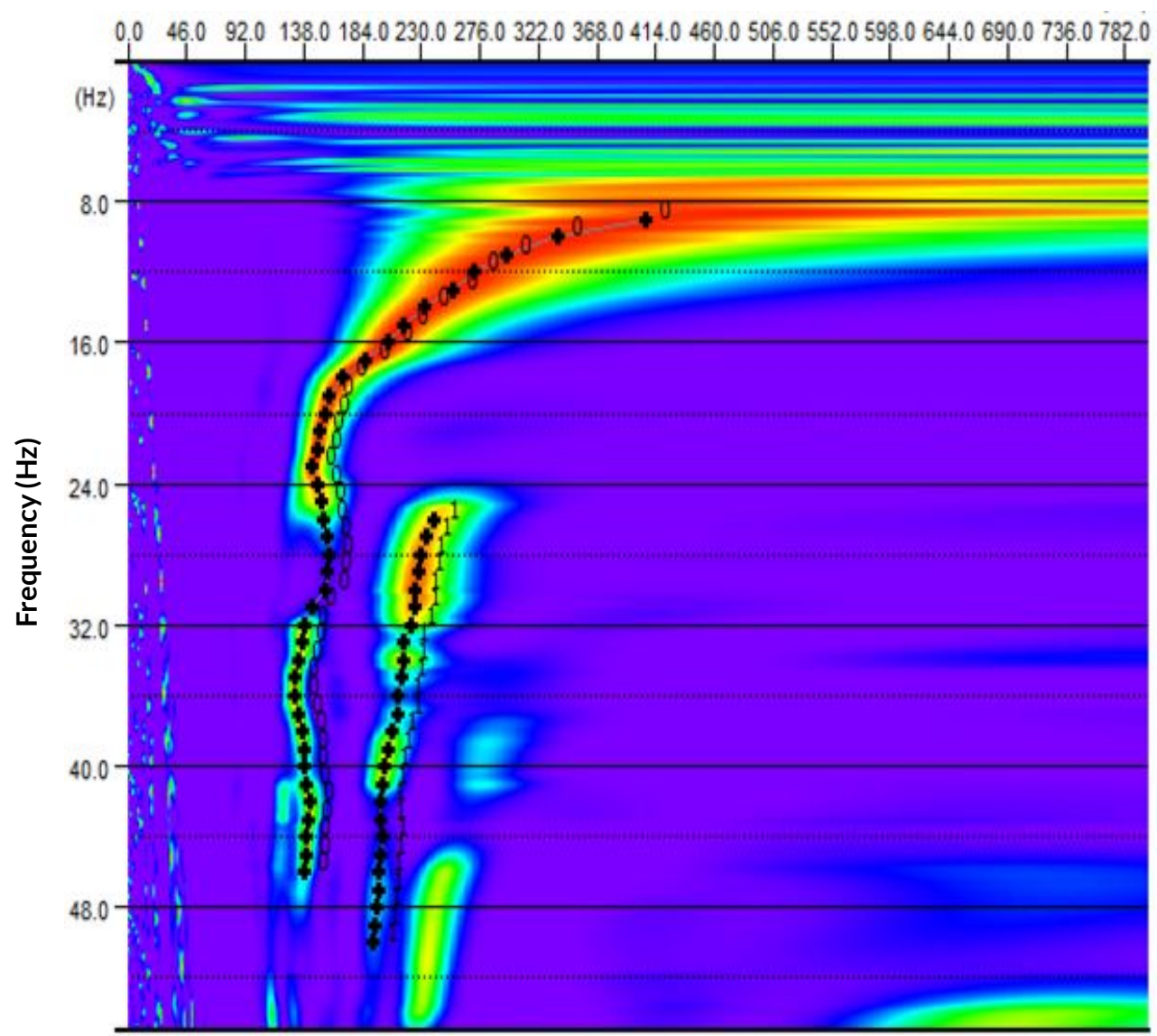


Dispersion

Curve Analysis

- Shot 18 dispersion curve

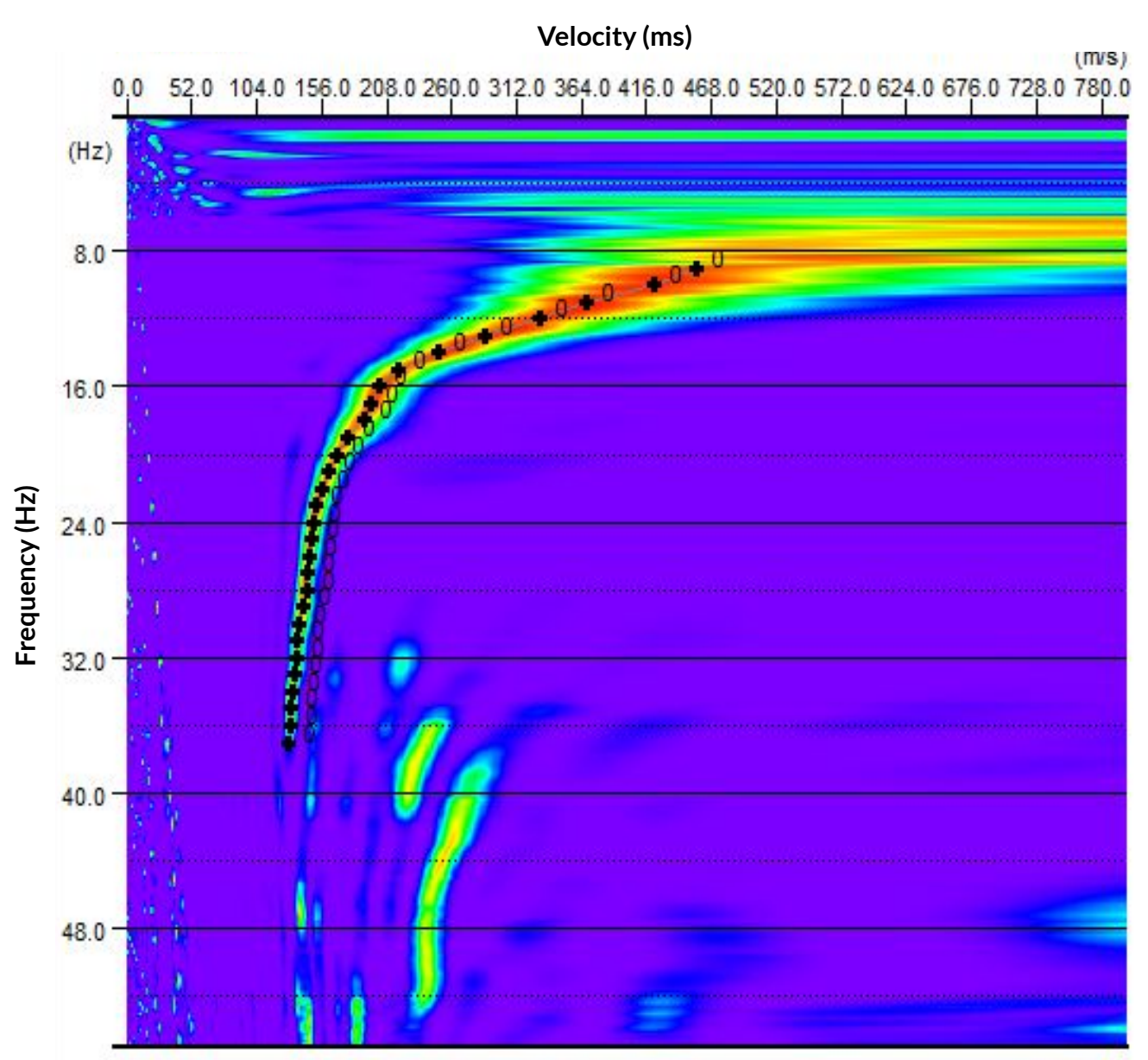




\section{Inversion}

Model Analysis

- $\quad$ Shot 12 inversion
Models (SH12.SGY)

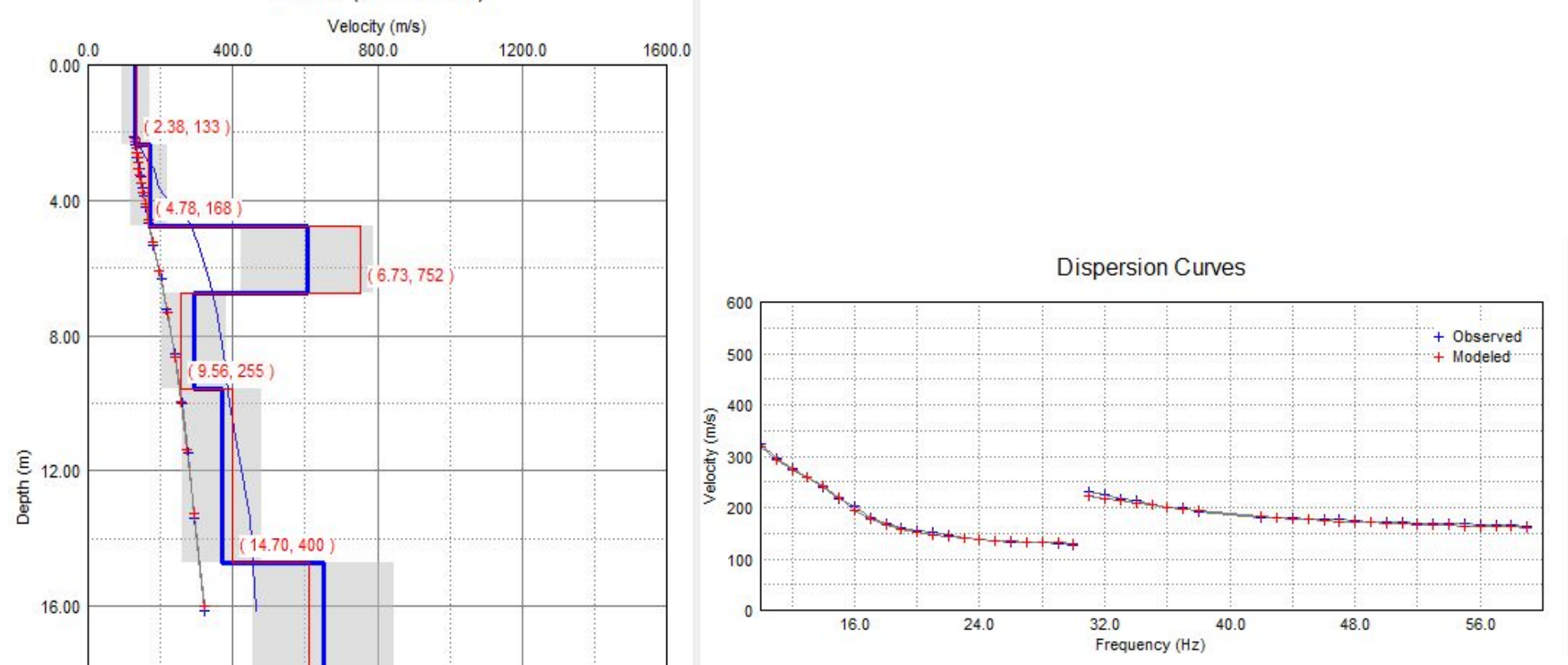




\section{Inversion}

Model Analysis

- $\quad$ Shot 13 inversion
Models (SH13.SGY)

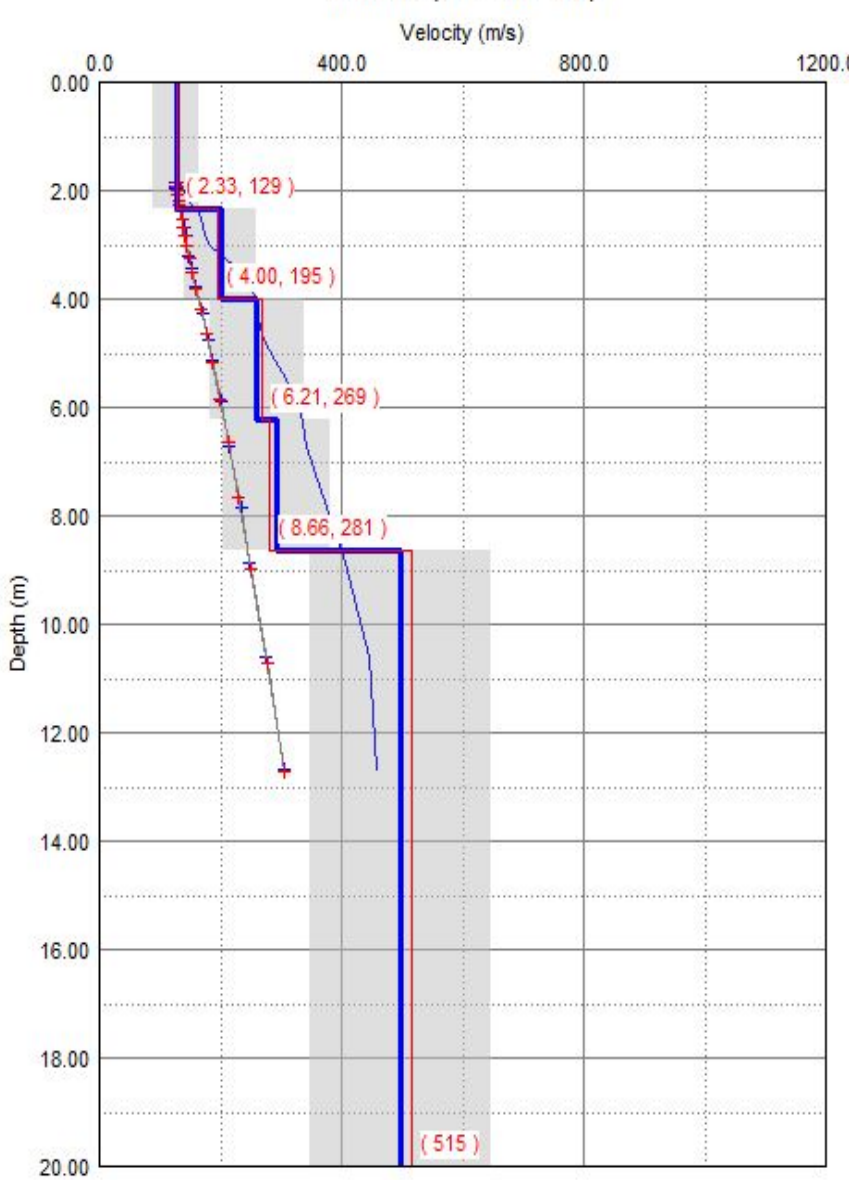

Dispersion Curves

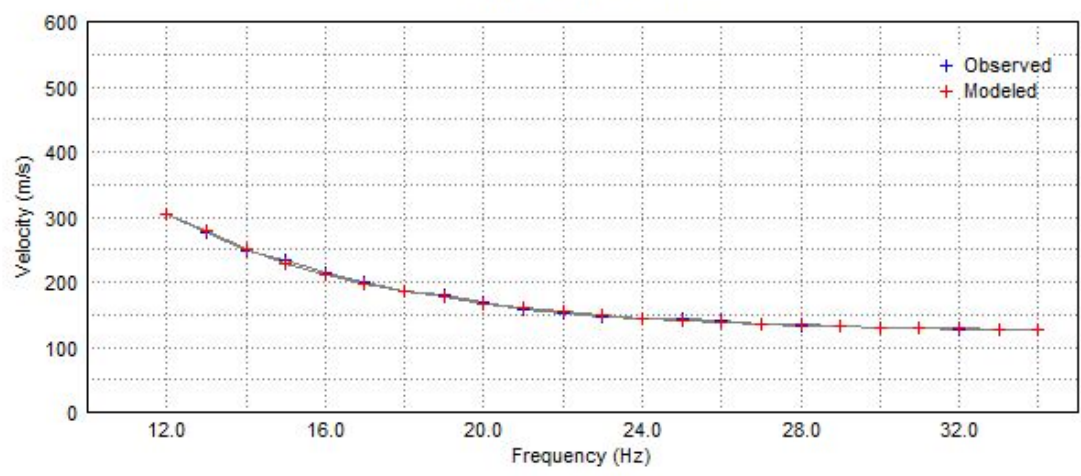




\section{Misfit Error}

- Each shot contains a misfit error percentage once the inversion process was finalized.

- A misfit percentage below 5 is most adequate because anything above is not a sufficient representation.

- $\quad$ Needs to be fixed through a more accurate dispersion pick.

- Overall, the RMS errors for each shot were on the lower end which means the dispersion picks were on target and the inversion models produced were reasonable, stable models.

- The results of the data should be interpretable because of this.

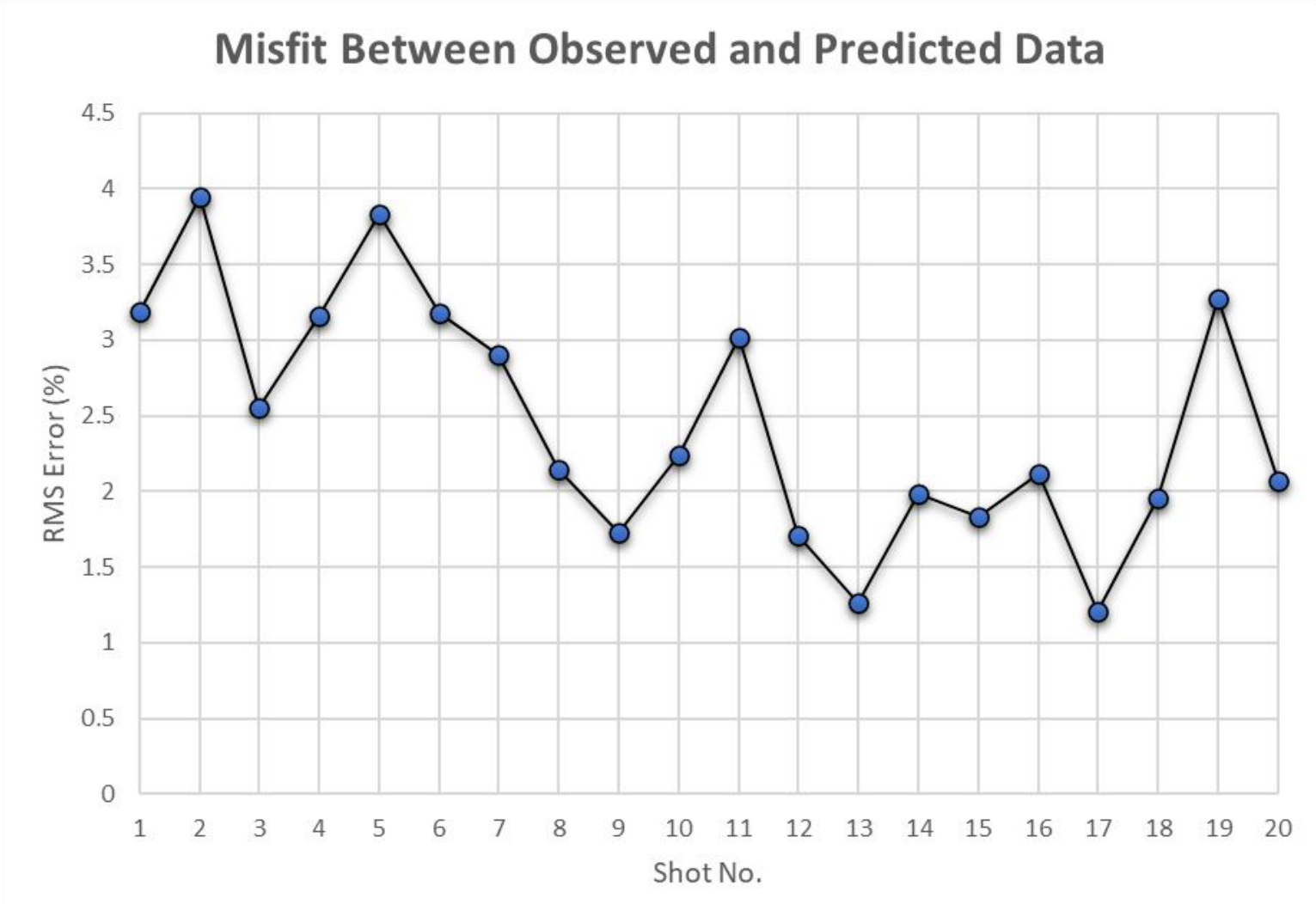




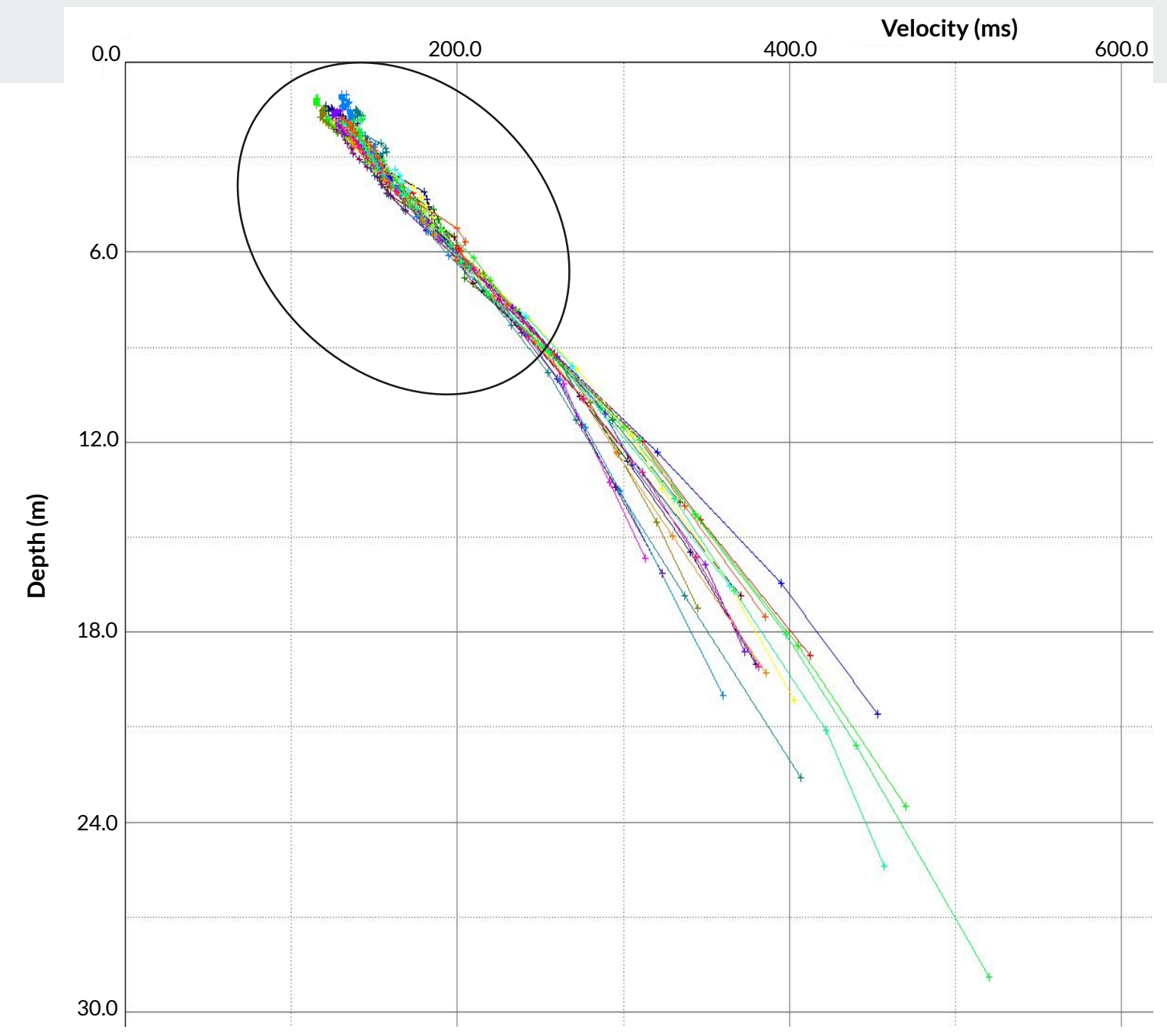

Inversion

Model Analysis

- 1D model 


\section{Velocity Model Results}

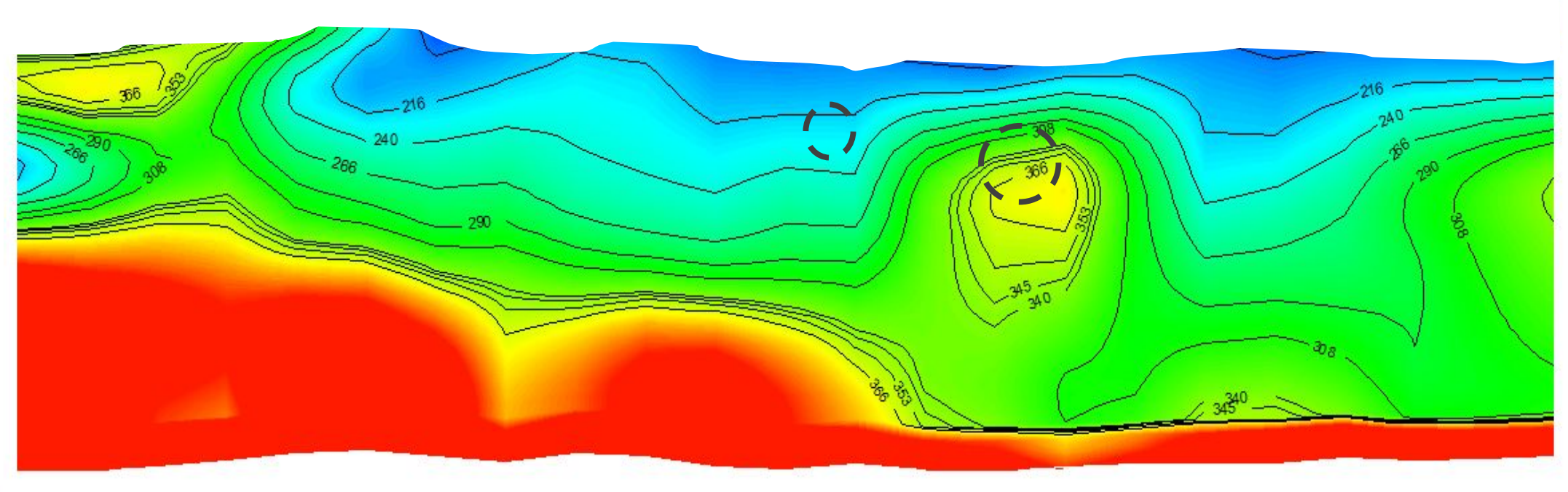




\section{Conclusion}

- With Multichannel Analysis of Surface Waves (MASW) Inversion, there is an anomaly observed in the subsurface between the depth of 2-4 m corresponding to the location of storm drainage pipe as high velocity.

- The MASW could not resolve the second anomaly, which is the smaller water pipe. This could be due to the data resolution as the diameter of the anomaly is much lower than the receiver spacing.

- Although shear wave velocity could determine the storm drainage pipe, a high velocity could represent the wall of the pipe or the disturbances in soil due to the excavation rather than the structure itself. 


\section{Acknowledgements}

- The University of Tennessee, Knoxville

- SEGSA

- Geogiga Seismic Pro 